Literatura y Lingüística $\mathrm{N}^{\circ} 25$

ISSN 0716-5811 / pp. 101-120

\title{
El hipertexto en la Enseñanza Media en Chile. ¿Es pertinente aplicar los enfoques textuales tradicionales?*
}

\author{
Teresa Ayala Pérez ${ }^{* *}$
}

\section{Resumen}

Los textos digitales constituyen parte importante de la comunicación en la sociedad de la información y recientemente han sido incluidos en los programas de Lenguaje y Comunicación de E.M. en Chile. Ante esta situación, cabe preguntarse si los tradicionales enfoques textuales, elaborados a partir del texto impreso en los años 70 y 80 y utilizados actualmente en Enseñanza Media, resultan aplicables al hipertexto. En este trabajo se describen algunos rasgos de este tipo de texto y se reflexiona sobre la posibilidad de aplicar al hipertexto los conceptos de criterios de textualidad, competencia textual y tipología textual en el ámbito escolar.

Palabras clave: hipertexto, texto digital, competencia textual, tipología textual, Lenguaje y Comunicación

\section{Hypertext in Secondary School in Chile: ¿It is pertinent apply traditional textual approaches?}

\begin{abstract}
Digital texts are an important part of communication in the information society and they have been recently included as Language and Communication contents in Chile. In this situation, it is possible to wonder if traditional textual approaches made from the printed text at 70's and 80's and used now in secondary school, are pertinent in the case of hypertext. This paper describes some text features and attempt to raise the possibility of applying hypertext concepts like textuality, textual competence and text typology in secondary education.
\end{abstract}

Keywords: hypertext, digital text, textual competence, textual typology, Language and Communication

Recibido: 29-08-2011 Aceptado: 29-12-2011

* El artículo se origina a partir de dos proyectos de investigación aprobados por la Dirección de Investigación de la Universidad Metropolitana de Ciencias de la Educación: "Aplicabilidad de los textos electrónicos en el aula de Lengua Castellana y Comunicación” (DIUMCE FIBAS-6/2009) y "Competencias digitales e hipertextuales de estudiantes de Pedagogía" DIUMCE (APEX 08/11), ejecutados en 2009 y 2011 respectivamente.

** Magíster en Lingüística. Doctora en Didáctica de la Lengua y la Literatura. Universidad Metropolitana de Ciencias de la Educación.teresa.ayala@umce.cl 
El hipertexto en la Enseñanza Media en Chile. ¿Es pertinente aplicar los enfoques textuales tradicionales? / Teresa Ayala

\section{Introducción}

La tradicional asignatura de Castellano cambió su nombre a "Sector Lenguaje y Comunicación" en el actual modelo educacional en Chile, y en él se incluyeron diversos contenidos que permitiesen abordar el proceso comunicativo desde una perspectiva más amplia que en los programas anteriores. En este contexto, se planteó como principal objetivo desarrollar la competencia comunicativa de los estudiantes, en tanto que su eje principal fue el texto. En 2009 el MINEDUC introdujo el llamado "Ajuste Curricular", dentro del cual se indica que se incluyen los "textos escritos como digitales", "textos en soportes impresos y electrónicos", "textos escritos y audiovisuales". En otras palabras, se intenta desarrollar la competencia comunicativa y las habilidades discursivas de los estudiantes, incluidos los generados en un ambiente digital y multimedial, pero cabe preguntarse hasta qué punto los enfoques textuales utilizados actualmente en Enseñanza Media, elaborados sobre la base de los textos impresos en las décadas del 70 y del 80, son aplicables a los textos electrónicos. Si sólo se considera el soporte digital (pantalla, teclado), no existen mayores diferencias respecto de un texto tradicional, pero si se trata del hipertexto, el tema se vuelve un tanto difuso. Por este motivo, en el presente trabajo se intenta revisar los rasgos generales del hipertexto, como asimismo los conceptos de criterios de textualidad, tipología textual y competencia textual con objeto de determinar si es posible aplicarlos al hipertexto en el ámbito escolar.

\section{Cambio de paradigma cultural}

Tal como aconteció con otras tecnologías, el sistema educacional ha debido adecuarse a las nuevas realidades que, en este caso, es la tecnología digital. La lectura tradicional ha dado paso a una lectura hipertextual y el profesorado, aun consciente de sus beneficios, todavía no tiene claro de qué manera abordarla, en parte porque solo los últimos años ha surgido bibliografía especializada y también debido a que se observa que los jóvenes leen muy poco y demuestran una baja comprensión lectora; sin embargo, cabe decir que los escolares leen bastante en formato digital, pero no necesariamente lo que exige la escuela, sino que con fines generalmente recreativos, pues estar constantemente conectados a Internet exige una lectura permanente. Para Gutiérrez Valencia (2006), la lectura electrónica presenta algunos beneficios, tales como que el "ciber-lector" adquiere el poder de des-estructurar y re-estructurar los textos originales; más del 90\% de la información que se produce a 
nivel mundial está en formato electrónico; el lector puede leer desde su hogar sin desplazarse a otros lugares; los textos electrónicos poseen una diversidad de opciones de búsqueda y recuperación; el e-reading brinda la posibilidad de poder combinar texto, imagen y sonido, etc. No obstante lo anterior, también este tipo de lectura implica algunas exigencias, como perfeccionamiento de las capacidades de lectura en texto impreso, dominio de Internet y de la WWW, habilidades para utilizar o navegar con diversos motores de búsqueda, capacidad para interactuar con distintos formatos textuales (libro electrónico, hipertexto), desarrollo de nuevos procesos de pensamiento o destreza para codificar y seleccionar información. Según Albarello (2011) entre otras diferencias, la lectura en pantalla es superficial, entrecortada, colectiva y conectiva, extensiva (diversos textos), abierta (hipertextual), focalizada, con interfaz multitarea, mientras que la lectura del texto impreso es profunda, continua, individual y aislante, intensiva (un solo texto), limitada al texto impreso, con lectura total y global, con interfaz especializada. Asimismo, en este entorno cultural, es importante considerar que el uso de dispositivos tecnológicos ha provocado cambios cognitivos en los más jóvenes. Según Carr (2010), si bien a primera vista la lectura de un texto en pantalla es similar a la de una página impresa, el solo hecho de desplazarse o hacer clic en un documento implica una expresión corporal y estímulos sensoriales muy diferentes de los que se activan al leer un libro o una revista. Como afirma Perrenoud (2007), hoy en día no se debería poder imaginar una pedagogía, o una didáctica del texto, sin ser consciente de las transformaciones que la informática produce en las prácticas de lectura y escritura.

\section{El hipertexto}

El texto se define por su autonomía y su cierre o conclusión como elementos esenciales; sin embargo, con el advenimiento de la sociedad de la información aparece el concepto de hipertexto, el cual -según Vandendorpe (2003)- parece haber abandonado el dominio de lo "cerrado y lo estable" para ubicarse bajo la categoría de "lo efímero y lo episódico". Para Rodríguez de las Heras (2006), el uso del prefijo hiper-supone señalar superioridad o exceso de aquello a lo que va unido, lo cual puede implicar que se trata de la extensión de un texto a partir de la creación de relaciones con otros textos, o bien que el texto adquiere una nueva dimensión, pero -en ambos casos- el hipertexto requiere un soporte digital para su escritura y su lectura: "si el adjetivo hipertextual realza la importancia de las estructuras textuales complejas, la interactividad nos 
El hipertexto en la Enseñanza Media en Chile. ¿Es pertinente aplicar los enfoques textuales tradicionales? / Teresa Ayala

orienta hacia la navegación dentro de las redes y al intercambio entre usuarios dentro de un modelo participativo muchos-a-muchos" (Scolari, 2008: 110). Todos los estudios respecto a este tipo de texto -aunque de naturaleza variada- coinciden en que el rasgo que lo identifica es su falta de linealidad, aunque se puede también señalar su conectividad, digitalidad y multisecuencialidad (Lamarca, 2006). Para Maingueneau (2007) la propia estabilidad material del texto es cuestionada por las nuevas tecnologías: "La misma pantalla no es más que una ventana abierta de manera inestable sobre un 'texto' que es perfectamente irrepresentable: es un 'hipertexto', una enorme red de relaciones virtuales que permite una cantidad ilimitada de recorridos distintos [...] (Maingueneau, 2009: 74). Pero, aunque el concepto de hipertexto es relativamente reciente, su aplicación es anterior a la Era Digital, puesto que en los textos impresos es posible encontrar referencias, notas a pie de página, tablas, etc. Para Lévy (1995), el hipertexto estaría constituido por 'nodos' (los elementos de la información, párrafos, páginas, imágenes, secuencias musicales, etc.) y de 'vínculos' entre estos nodos (referencias, notas, apuntadores, "botones" que señalan el paso de un nodo a otro); la lectura de una enciclopedia clásica, por ende, ya era hipertextual,

ya que utilizaba diccionarios, léxicos, índices, thesaurus, atlas, tablas numéricas, índices de materias y notas de referencias al final de los artículos, instrumentos, todos ellos, de orientación. Sin embargo, el soporte digital aporta una diferencia considerable en relación a los hipertextos anteriores a la informática: la búsqueda en los índices, el uso de los instrumentos de orientación, el paso de un enlace a otro se hacen con una gran velocidad, del orden del segundo. Por otro lado, la digitalización permite asociar en un mismo medio y mezclar sutilmente sonidos, imágenes animadas y textos. El hipertexto digital, según esta primera aproximación, se definiría por lo tanto como una colección de informaciones multimodales dispuestas en una red de navegación rápida e "intuitiva" (Lévy, 1999: 32).

Theodor Holm Nelson acuñó el concepto de hipertexto y la idea del hipervínculo propiamente tal la propuso en 1965 cuando dictó la conferencia "Complex Information Processing: a File Structure for the Complex, the Changing an the Indeterminate". . En este trabajo Nelson afirma:

1 Texto completo en http://www.scribd.com/doc/454074/A-File-Structure-for-the-ComplexThe-Changing-And-the-Indeterminate

104


Let me introduce the Word "hipertext"** (sic) to mean a body of written or pictorial material interconnected in such a complex way that it could not conveniently be presented or represented on paper. It may contain summaries, or maps of its contents an their interrelations; it may contain annotations, additions and footnotes from scholars who have examined it ${ }^{2}$ (Nelson, 2003: 134).

En Literary Machines (1981) Nelson habla de la "lectura no secuencial" como rasgo principal del hipertexto, pues el lector puede navegar libremente en forma no lineal, permite la existencia de varios autores y desliga las funciones de autor y lector: "Con 'hipertexto' me refiero a una escritura no secuencial, a un texto que bifurca, que permite que el lector elija y que se lea mejor en una pantalla interactiva" (Nelson, 1981: 2, en Calvo Revilla, 2002). Nelson también proyectó un sistema cuya idea básica era crear un documento global y único que llamó docuverse ('documental universe'), formado por una red de computadores con toda la información que pudiera existir a la que se podía acceder en forma de hipertexto, pues se podía extraer sin que el documento original perdiera su copyright. Este proyecto recibió el nombre de Xanadú ${ }^{4}$ que duró cerca de treinta años, pero que no logró consolidarse debido a que el sistema World Wide Web fue el que terminó imponiéndose.

\subsection{El hipertexto y la Web}

En realidad, fue el advenimiento de la tecnología de Internet la que facilitó el hecho de que el hipertexto se convirtiera en el eje de la sociedad de la información. La comunicación escrita pasó de limitarse de un texto impreso a la posibilidad de usar también un texto digital, lo que incluyó desde el correo electrónico hasta los periódicos en línea. Las tecnologías permitieron el uso del texto digital, es decir, codificado en bits (binary digit), a través de dispositivos que permiten su transmisión o grabación. Si este texto digital contiene enlaces a otros textos, entonces debe ser considerado como hipertexto, cuya existencia ha sido posible gracias a varios hechos

2 "Permítanme introducir el término "hipertexto" ** (sic) para designar un cuerpo de material escrito o pictórico interconectado en forma tan compleja que no puede ser convenientemente presentado o representado en papel. Puede contener resúmenes o mapas de su contenido y sus interrelaciones; puede contener anotaciones, adiciones y notas al pie de los académicos quienes lo han examinado" (Nelson, 2003: 134).

3 "[...] "hypertext" I mean non-sequential writing -- text that branches and allows choices to the reader, best read at an interactive screen".

4 El sitio http://www.xanadu.net/mantiene la idea original de 1966 y se define como "el proyecto original de hipertexto". Su nombre, al parecer, fue tomado de un poema donde se habla de "ese mágico sitio de la memoria literal donde nada se pierde nunca". 
El hipertexto en la Enseñanza Media en Chile. ¿Es pertinente aplicar los enfoques textuales tradicionales? / Teresa Ayala

que permiten su desarrollo, como la creación de los microprocesadores, la masificación de los computadores personales, el desarrollo del Protocolo de Internet (IP) y el Protocolo de Transmisión ${ }^{5}$ (TCP), cuyo servicio más importante es el protocolo de transferencia de hipertexto (http 'hipertext transfer protocol'), que permite crear vínculos en cadenas que forman la base de la World Wide Web, creada por Tim Berners-Lee. En 1993 se unificó el lenguaje web gracias al Hypertext Markup Language (HTML) que aún hoy se usa (Zanoni, 2008) y la comunicación a través de las redes resulta exitosa, entre otros motivos, porque el lenguaje HTML que diseñó Berners-Lee, además de la simplicidad de su uso, es un lenguaje de hipertexto que puede anclar o redirigir al lector desde un punto cualquiera del texto a otro lugar, mediante los llamados links o enlaces. Además de lo anterior, Gutiérrez (2008) afirma que la filosofía con que fue creada la Web puede resumirse en tres principios básicos: todos pueden publicar, todos pueden leer, nadie debe restringir.

\subsection{Características del hipertexto}

El rasgo más evidente del hipertexto es su falta de linealidad que permite a los usuarios recorrer el documento de diferentes maneras; es eminentemente interactivo, pues permite a cada usuario seleccionar los temas de su interés; es multimodal (tomando el concepto de Kress y van Leeuwen ${ }^{6}$ 1996, 1998, 2001), pues está configurado por elementos verbales y no verbales conectados entre sí que ofrecen distintas opciones al lector y que permite una lectura no lineal o bien multilineal, aunque esta falta de linealidad no es aleatoria ni tampoco implica falta de coherencia y cohesión. El lector puede realizar diferentes elecciones, en tanto que la organización de las páginas no sigue un orden fijo y contiene enlaces o hipervínculos con un número prácticamente ilimitado de otras páginas, sin que ninguna de ellas sea la primera o la última. Esta característica puede ser considerada como positiva, pues permite acceder a múltiples fuentes de información, pero también puede ser considerado como un factor negativo cuando el usuario, ante esta inmensa cantidad de información, no sabe cuál es la más relevante. De acuerdo con Vandendorpe (1999), en informática

5 Tecnología desarrollada por Vinton Cerf en 1973.

6 Kress, Gunther \& Theo van Leeuwen (1996): Reading Images: The Grammar of Visual Design. London: Routledge; Kress, Gunther \& Theo van Leeuwen (1998): 'Front Pages: (The Critical) Analysis of Newspaper Layout'. In Allan Bell \& Peter Garrett (Eds.): Approaches to Media Discourse. Oxford: Blackwell, pp. 186-219; Kress, G. y Leeuwen Van. T. (2001) Multimodal Discourse: The Modes and Media of Contemporary Communication Discourse. Londres, Arnold.

106


la noción de hipertexto representa una manera de relacionar directamente entre sí informaciones diversas, de orden textual o no, situadas o no en un mismo fichero (o una misma "página"), con ayuda de enlaces subyacentes. Gracias a una interfaz que deja un gran sitio a los elementos visuales e intuitivos, como el color y los íconos, el usuario de un hipertexto puede localizar los lugares de un documento donde están injertadas informaciones suplementarias y acceder a ellas directamente con ayuda de un simple clic del Mouse (Vandendorpe, 2002: 95).

Para Calvo Revilla (2002), el hipertexto es un medio informático que relaciona información tanto verbal como no verbal al almacenar caracteres, imágenes y sonidos y relacionar los distintos elementos con facilidad; sus nexos electrónicos unen lexías tanto "externas" a un texto dado (por ejemplo, un comentario del mismo por otro autor, textos paralelos o comparativos), como internas, creando así un texto multilineal o multisecuencial. Cabe agregar, además, que si bien el hipertexto es multilineal, ofrece diversas lecturas a los usuarios, pero en el proceso de construcción, el autor usualmente debe elaborar un "mapa" estructurado ${ }^{7}$ que le dé consistencia y, desde esta perspectiva, la falta de linealidad se aplicaría sólo a la lectura. Para Landow, el hipertexto es "un medio informático que relaciona información tanto verbal como no verbal", cuyos nexos electrónicos unen lexías tanto internas como externas, creando así un texto "que el lector experimenta como no lineal o, mejor dicho, como multilineal o multisecuencial" (Landow, 1995: 15). Si se considera que para Lotman y Uspenski (2000: 187) los cambios en el sistema de la cultura están ligados a una ampliación de los conocimientos de la colectividad humana, es indudable que la colección de documentos hipertextuales que configuran la Web contribuye a ampliar de forma notable el caudal de saberes que la humanidad puede llegar a adquirir. Desde otra perspectiva, para los estudios discursivos el hipertexto es un tipo de intertexto. La intertextualidad supone la presencia de un texto dentro de otro texto, en tanto que la hipertextualidad es la operación por medio de la cual un texto (denominado hipotexto) se incorpora a un texto anterior (denominado hipertexto) sin que sea un comentario (Maingueneau, 1996).

7 La forma de estructurar un contenido digital suele ser denominado como estructura de la información, que se relaciona no solo con el diseño, sino también con la usabilidad de una aplicación informática. 
El hipertexto en la Enseñanza Media en Chile. ¿Es pertinente aplicar los enfoques textuales tradicionales? / Teresa Ayala

\section{Criterios tradicionales de textualidad y su aplicación al hipertexto}

En los años 70 la Lingüística del Texto amplió los límites de la lingüística y se orientó hacia las gramáticas transfrásticas. Entre los aspectos más relevantes de este período se encuentra el de los llamados criterios de textualidad (Beaugrande y Dressler, 1972): cohesión, coherencia, intencionalidad, aceptabilidad, informatividad, situacionalidad e intertextualidad. Estos criterios son parte de la enseñanza del lenguaje en Chile $y$, a pesar de que puedan ser considerados superados por la academia, mantienen su vigencia en el sistema escolar. Con relación al hipertexto, es posible afirmar que cumple con todas las características atribuidas al texto impreso y, además de los criterios de textualidad mencionados, se sustenta en tres principios que regulan la comunicación textual: eficacia, efectividad y adecuación. Por otra parte, el texto se caracteriza por su carácter comunicativo, por su carácter pragmático, ya que se produce en un determinado contexto extralingüístico y por su estructura. De acuerdo con lo anterior, es posible decir que un hipertexto comunica algo con una intención determinada; se produce en un contexto extralingüístico específico que le da sentido y posee una organización interna que garantiza el significado del mensaje, independientemente si se trata de una página web, un sitio web, un portal, un blog, un correo electrónico, un mensaje dentro de una red social, etc.

Desde la perspectiva de los criterios de textualidad, la coherencia y la cohesión se constituyen en los más importantes y, en el caso de los textos digitales -independientemente de su no-linealidad o multilinealidad-, deben ser igualmente respetadas para que puedan ser comprendidos por un lector. De esta manera, en el caso de la usual acción de cortar y pegar, un "emisor-usuario" con escasa competencia textual cortará y pegará fragmentos de textos sin lograr con ello un texto coherente y cohesivo, problema frecuente que observan profesores de Enseñanza Media y Enseñanza Superior en los trabajos de los estudiantes. El hecho de seleccionar un fragmento textual tomado de Internet indica que hay comprensión lectora, pero en el proceso de producción textual, la falta de unión (cohesión) entre las partes provocará una incoherencia textual. Respecto de la aplicación de los cinco criterios restantes mencionados por Beaugrande y Dressler, el texto digital debe poseer aceptabilidad, pues debe resultar apropiado para un contexto determinado, el cual puede ser el entorno cultural donde se produce o bien el entorno digital en el que funciona (un blog, un sitio, un portal, un mensaje de chat,

$+108$


un correo electrónico, etc.); debe tener en consideración la diversidad lingüística y ser "adecuado" según se trate de un mensaje entre amigos a través de Messenger, un correo electrónico o bien cuidar la formalidad en una wiki. Si se trata de la intencionalidad, todo texto, independiente de su naturaleza, posee una intención comunicativa que su autor intenta dar a conocer, por lo cual debe utilizar las estrategias adecuadas para el logro de su objetivo, en tanto que el receptor debe seguir dichas "pistas" para una cabal comprensión. En el caso de los hipertextos, las estrategias no sólo son lingüísticas, sino también visuales, por lo que los usuarios deben conocer los diferentes códigos utilizados, tales como la tipografía, los colores, la distribución espacial, el uso de imágenes, emoticones, etc. En cuanto a la informatividad, dependiendo de la naturaleza del propio texto, dicha información puede no ser lingüística y entregarse a través del uso de diferentes estrategias visuales. La situacionalidad es aplicable a los textos digitales, puesto que, por ejemplo, un mensaje de Twitter, que sigue el esquema de responder a la pregunta "¿Qué está pasando?", sólo cobra sentido si es adecuado a la situación que se está produciendo en ese mismo momento. Finalmente, el criterio de intertextualidad es quizá el más característico del hipertexto, pues por definición es un texto que se relaciona con una cantidad indeterminada de otros textos a través de vínculos que forman la colección de textos World Wide Web. Por estas razones, no existiría problema para aplicar los criterios de textualidad a los textos digitales, pues no sólo los mantienen, sino que incluso, en algunos casos, pueden realizarse de forma mucho más evidente que en los textos impresos, por lo cual los profesores de Lenguaje tienen a su disposición una fuente inagotable de materiales para poder llevar a cabo propuestas pedagógicas acordes con la realidad tecnológica y cultural de los estudiantes.

\section{Macrorreglas y macroestructuras en el hipertexto}

Un aspecto importante en el proceso de comprensión y producción de textos es determinar de qué se trata. Los postulados de van Dijk de los años 80 siguen siendo de gran ayuda a los profesores de Enseñanza Media, por lo cual son usualmente aplicados. Entre los aspectos considerados se encuentra el hecho de que para van Dijk (1988), luego de leer o escuchar un discurso, es posible señalar su tema, es decir, asunto, resultado e idea general o bien qué es lo importante lesencial de lo que se dijo. Estos conceptos son abordados en Enseñanza Media por cuanto el discurso se hace explícito en términos de un cierto tipo de estructuras que aparentemente no se expresan en oraciones individuales, sino en 
El hipertexto en la Enseñanza Media en Chile. ¿Es pertinente aplicar los enfoques textuales tradicionales? / Teresa Ayala

secuencias completas de oraciones que van Dijk llama macroestructuras semánticas, esto es, la reconstrucción teórica de nociones como "tema" o "asunto" del discurso. Junto al concepto de macroestructura, usado para dar cuenta del contenido global de un discurso, van Dijk emplea el de microestructura para denotar la estructura local de un discurso, es decir, de las oraciones y las relaciones de conexión y de coherencia entre ellas. Por otra parte, postula la presencia de reglas establecidas a partir del vínculo entre una microestructura y una macroestructura y las llama macrorreglas: supresión, generalización y construcción. Se trata de procesos que le permiten al lector suprimir información, generalizarla y reconstruirla con objeto de sintetizar y comprender lo leído, extrayendo lo que considera innecesario y manteniendo lo que estima relevante. Llevado al terreno hipertextual, el lector-usuario de un texto digital realiza inconscientemente este proceso que le permite captar el contenido ("sentido") global de una página web, un blog, un correo electrónico, etc., pero también el significado de sus partes constitutivas, a pesar de que puede ser definida como un tipo de lectura superficial y fragmentada. Si el autor de una página web o de un blog desea atraer y cautivar a muchos "ciberlectores", debe utilizar macroestructuras semánticas que le indiquen a este lector potencial el contenido de dicho texto, a través de un título o nombre que resuma todos los elementos que incluye el mensaje completo. Es lo que sucede con los titulares de los periódicos electrónicos, especialmente los de la portada (o front page), cuya misión es atraer lectores que se interesen de tal manera que deseen proseguir la lectura a través de los párrafos siguientes. Los blogs personales suelen tener un nombre propio que usualmente indica el tipo de contenido que entregan, pero cada comentario o nuevo aporte también tiene su propio título, que es el que aparece en los motores de búsqueda. Los blogs no necesariamente tienen nombres específicos, pero si se desea lograr la atención de los lectores, es importante que su denominación le comunique al receptor el tipo de tema que aborda. Por otra parte, cuando se trata de los correos electrónicos, el "asunto" o "subject" corresponde también a una macroestructura semántica, o bien a la aplicación de una macrorregla (supresión, generalización o construcción). En el caso de los microbloggins, debido a que el texto no debe superar los 140 caracteres, el emisor debe resumir la información a partir de la pregunta inicial "¿Qué está pasando?", por lo cual también aplica macroestructuras o macrorreglas, al igual que en los SMS (mensajes de textos a través del teléfono celular).

$+110$




\section{Tipologías textuales}

Las tipologías textuales surgidas en los años 80 y 90 son parte fundamental de los contenidos mínimos y objetivos fundamentales de Enseñanza Media en Chile y uno de los problemas que surgen con la inclusión de los textos digitales en el sistema escolar es que estos son de naturaleza muy diversa: un documento elaborado en procesador de texto es, por una parte, un texto tradicional que puede ser impreso, pero al ser elaborado en un medio electrónico, haber sido codificado a través de bits, donde además pueden abrirse varias ventanas, incorporarse imágenes o hipervínculos, se convierte en un hipertexto. Por el contrario, un microbloggin o un chat son textos cuya producción y lectura solo se dan en un ambiente digital, pero aun así deben ser coherentes y cohesivos para que puedan ser entendidos por los lectores. Un blog es hipertextual por definición y no tiene un correlato impreso, a pesar de su naturaleza de "bitácora", pues consta de varios elementos que se dan de forma simultánea: links, buscador, calendarios, artículos anteriores, archivos, etc. Una página web variará según sea una página simple, un sitio web o un "portal". Por otra parte, todos los tipos de textos pueden ser elaborados y leídos en formato digital, pues los textos informativos, periodísticos, literarios, publicitarios, etc. aparecen en distintos ambientes informáticos: páginas web, blogs, servicios de mensajería, microbloggins, foros, etc. Esta situación cobra especial importancia en el contexto educativo en Chile, debido a que la tipología textual es el eje articulador de los Planes y Programas de la asignatura de Lenguaje, especialmente dentro del paradigma planteado en el Ajuste Curricular (2009), donde se mencionan enunciados tales como "Leer comprensivamente, con distintos propósitos, textos en soportes impresos y electrónicos", "Producción de textos escritos y audiovisuales ajustados a propósitos y requerimientos del nivel, que pueden incluir, por ejemplo: autorretratos, informes de lectura, afiches o anuncios publicitarios y propagandísticos, mensajes por correo electrónico, participaciones en foros coloquiales en Internet, blogs personales, presentaciones en power point" (MINEDUC, 2009: 39).

De acuerdo con las diferentes propuestas sobre tipologías textuales, se entiende que un texto es un conjunto de secuencias textuales y, según el tipo que domine, representará el esquema principal. Dentro de los diferentes planteamientos es posible citar a Adam (1985, 1991), quien

8 Sitio web cuyo objetivo es ofrecer al usuario una serie de recursos y servicios, como buscadores, foros, documentos, etc. 
El hipertexto en la Enseñanza Media en Chile. ¿Es pertinente aplicar los enfoques textuales tradicionales? / Teresa Ayala

en principio distingue ocho tipos de texto, pero posteriormente elimina algunos y relaciona los tipos de textos con grandes tipos de actos de habla, por lo cual considera que los textos pueden ser mixtos. Debido a que son las "estructuras textuales" las que predominan en un texto, eventualmente algunos pueden darse en forma pura, pero también que en un mismo texto pueden aparecer diferentes tipos de secuencias, por ejemplo, las descriptivas, que suelen estar asociadas a las estructuras narrativas. Adam (2001) afirma que "J'ai dit plus haut qu'il me paraissait présomptueux de parler de 'typologie des textes'. Les sceptiques sont généralment découragés par le fait que chaque texte est une réalité beaucoup trop hérérogène pur qu'il soit posible de l'enfermer dans les limites d'une définition stricte" (Adam, 2009: 19).

Como se dijo, todo tipo de texto puede ser elaborado, leído o reproducido en soporte electrónico o digital, por lo cual el trabajo con hipertextos no requiere una reelaboración de lo ya existente en este ámbito; sin embargo, es posible también considerar que, por ejemplo, en foros y grupos (como Google Grupos) el texto argumentativo se da de forma natural, mientras que en la comunicación a través de Messenger y salas de chat los textos son eminentemente dialógico-conversacionales. Los perfiles de Facebook o las homepages son muestra de textos descriptivos, en tanto que tutoriales y wikis constituyen ejemplos de textos expositivoexplicativos. Los textos narrativos, en tanto, pueden aparecer en todo tipo de hipertextos, desde blogs personales, correos electrónicos, SMS, diarios electrónicos, etc. En resumen, el profesor de Lenguaje y Comunicación puede obtener ejemplos de todo tipo de textos en la propia Red, porque se reproducen textos impresos o porque son textos que sólo existen en un ambiente digital, por lo que cualquier propuesta pedagógica puede incluir a los hipertextos sin abandonar por esta razón los contenidos tradicionales de la asignatura. Además de lo anterior, y en términos generales, la comunicación a través de aplicaciones tecnológicas tiene diferencias en varios planos (Cabedo Nebot, 2009): según el número de participantes (en roles de emisor o receptor), si es o no dialógico, la forma de distribución y si hay o no sincronía en este proceso. Por tales razones, los profesores deben enfrentar con una mirada diferente el trabajo pedagógico con textos electrónicos y no forzar el paralelismo entre los dos ambientes comunicativos (digital e impreso).

9 "He dicho antes que me parecía presuntuoso hablar de "tipología de textos." Los escépticos son generalmente desalentados por el hecho de que cada texto es una realidad heterogénea demasiado pura que sólo es posible de captar dentro de los límites de una definición estricta" (Adam, 2009: 19).

112




\section{Competencia textual}

El propósito del actual paradigma educativo en torno a la enseñanza de la lengua es el desarrollo de la competencia comunicativa, concepto acuñado por Hymes en The Ethnography of Communication (Hymes y Gumperz, 1964) y Foundations in Sociolinguistics. An Ethnographic Approach (1974). En los años siguientes, otros autores retoman el concepto de competencia comunicativa, como Canale y Swain (1980) y Canale (1983), quienes distinguen varias subcompetencias, tales como la competencia gramatical, competencia sociolingüística, competencia discursiva y competencia estratégica. Respecto de las competencias relativas al texto, Bassols y Torrent (2003: 12) sostienen que "El joven emisor o receptor de un texto escrito -para ser leído o escuchado- ha de aprender cómo es la trama, el tejido interno que liga las diversas unidades -desde la palabra hasta el párrafo- que lo componen"; dicha capacidad es la competencia discursiva de un hablante; sin embargo, existiría otra competencia en relación al texto, la llamada competencia textual propuesta por Adam (1985), y que otros autores llaman metatextual, que se refiere a la capacidad de averiguar frente a qué tipo de textos nos encontramos.

Todo lo anterior constituye la base de la enseñanza de la lengua en la actualidad, sin embargo, puede resultar insuficiente si no se aplica también al hipertexto, razón por la cual cabe preguntarse si resulta pertinente aventurarse a formular una competencia hipertextual. Para Prado Aragonés (2001), el complejo ámbito comunicativo surgido del actual entorno tecnológico y las destrezas necesarias para desenvolverse y navegar por las redes de información implica que los objetivos comunicativos que se deben plantear en el proceso de enseñanza-aprendizaje tienen que contemplar el desarrollo de capacidades acordes con las necesidades comunicativas y formativas que la sociedad actual demanda; sin embargo, dichas capacidades van más allá de los límites tradicionales de la competencia comunicativa y "configuran un nuevo concepto de competencia más amplio, en el que confluyen capacidades lingüísticas, semiológicas y tecnológicas. Es lo que constituye la competencia hipertextual" (Andrea, 2000, en Prado Aragonés, 2001: 25). Las capacidades que sugiere Prado Aragonés son: conocimiento de nuevos códigos multimedia en interacción con códigos lingüísticos tradicionales; estrategias para la búsqueda, selección, organización y tratamiento de la información; destrezas de lectura y comprensión de la información, además de expresión y elaboración, adecuada a los nuevos formatos hipertextuales utilizados por las 
El hipertexto en la Enseñanza Media en Chile. ¿Es pertinente aplicar los enfoques textuales tradicionales? / Teresa Ayala

nuevas tecnologías; espíritu crítico que permita la adecuada selección y tratamiento de la información; capacidad de autonomía y autogestión en el proceso de aprendizaje; habilidad para la interacción, la participación activa y la toma inmediata de decisiones; espíritu abierto y multicultural que posibilite la comunicación interpersonal entre hablantes de países y culturas diferentes; talante participativo y trabajo en colaboración. Puede observarse que estas capacidades van más allá del ámbito textual y se refieren más bien a las llamadas "habilidades del siglo XXI"10, por lo que, si bien constituyen un punto de partida, para lograr determinar qué es lo que implica la competencia hipertextual se hace necesario establecer un paralelo con la competencia comunicativa en general y con la subcompetencia textual en particular.

Debido a que la competencia comunicativa está compuesta por el conocimiento lingüístico y paralingüístico, el lector-usuario de hipertextos debe utilizar las normas que rigen su idioma, como también aspectos no verbales y paralingüísticos que poseen significados convencionales en cada comunidad hablante que, en este caso, pueden manifestarse a través de signos utilizados por los internautas como los emoticones (emotional icons), más conocidos como "caritas felices" o "smilies", que suelen incluirse en correos electrónicos, foros y chats. Además, cuando un usuario sube una foto suya a Fotolog o Flickr, suele adoptar una conducta no verbal con una determinada intención comunicativa que sabe será adecuadamente decodificada por quienes vean dicha imagen en la Web. La competencia comunicativa también implica habilidades interaccionales, es decir, conocimiento y expectativas respecto de quién puede hablar en ciertas situaciones, cuándo no debe hacerlo, con quiénes se puede hablar, cómo se debe hablar con personas de distintos status y roles, etc.; en un hipertexto el usuario sabe cuándo puede manifestar su opinión, por ejemplo, en un foro o en un blog a través de los llamados post y cuándo no debe hacerlo; sabe, además, que no puede criticar a una figura mediática en un blog o página web dedicada a enaltecer a ese personaje; el internauta conoce los "rituales" usados en Messenger y sabe que debe esperar que su interlocutor termine de escribir su mensaje antes de responderle; también es una convención no utilizar mayúsculas en un foro o e-mail porque los destinatarios lo decodificarán como una agresión en la que el emisor les está gritando. Un escolar

10 Ver http://www.21stcenturyskills.org/documents/P21_Framework.pdf; Germán Escorcia, "Reinventar el aprendizaje. Habilidades para el Siglo XXI. Estrategia C5, en http://www.eduteka. org/EstrategiaC5.php3.

114


sabe que no debe incluir "caritas felices" si envía un correo electrónico de tipo institucional o administrativo y que sólo puede hacerlo cuando se comunica con amigos; también sabe que generalmente es necesario escribir un "asunto" o subject cuando envía un e-mail, porque muchas personas no abren el correo si no saben de qué se trata el mensaje. De acuerdo con Yus (2010), se acuñó el concepto de ciberpragmática en 2001 para el estudio de este tipo de comunicación e incluso se aplican los estudios sobre cortesía (Lakoff, 1973; Leeach, 1983, Brown y Levinson, 1987), la cual se denomina en Internet netiquette (de net y etiquette), que puede traducirse como cibermaneras. Un usuario habitual de foros sabe que para emitir su opinión debe primero registrarse, al igual que los lectores de diarios electrónicos cuando desean postear respecto de un artículo de opinión, pues de otra forma ni siquiera podrán acceder a la plataforma digital. Si se considera que la competencia comunicativa implica conocimiento cultural, ello involucra el conocimiento de las estructuras sociales, valores y actitudes acerca del lenguaje y formas de habla, entonces el lector-usuario de hipertextos sabe que el lenguaje que utiliza en una sala de chat, en los mensajes de textos (SMS) o en Messenger puede ser informal, e incluso codificado para comprimir el mensaje en pocos caracteres, por ejemplo, xat 'chat', bstnt 'bastante', st 'este', fsta 'fiesta', como también los emoticones, por ejemplo, :-)) 'muy feliz, :-X 'un beso', :-( 'triste', etc.

Por otra parte, si se toman como base los argumentos que permiten establecer la competencia textual, es posible realizar un correlato paralelo, poniendo énfasis en que tanto en el texto como en el hipertexto esta competencia se aplica tanto a la función del hablante-oyente, emisorescribiente o receptor-lector, pero en el caso del texto digital se puede utilizar el concepto de lector-usuario ${ }^{11}$. Así, (1) si el hablante-oyente puede parafrasear un texto, el lector-usuario puede aprehender el contenido global de un hipertexto; (2) si el hablante-oyente puede distinguir entre un conglomerado de enunciados y un texto coherente, el lector-usuario puede distinguir si se trata de un hipertexto coherente o una serie de enunciados inconexos; (3) si el hablante-oyente puede advertir, en gran medida, si un texto está incompleto o interrumpido, a pesar de que la lectura del hipertexto no es lineal, el lector-usuario puede darse cuenta si en cada página, sitio o blog la información está completa o debe remitirse, a través de un link o el uso del mouse, a otro hipertexto; (4) si el hablante-oyente puede atribuir un título a un texto o viceversa, en el

11 Concepto sugerido por Lamarca Lapuente (2006) 
El hipertexto en la Enseñanza Media en Chile. ¿Es pertinente aplicar los enfoques textuales tradicionales? / Teresa Ayala

caso del correo electrónico, el lector-usuario puede fácilmente escribir el "asunto" o subject, que resume en pocas palabras el contenido de un e-mail, o poner un título al post que envía a un periódico o foro; (5) si el hablante-oyente puede clasificar los distintos tipos de texto, el lectorusuario distingue entre un correo electrónico, foro, página web, blog o cualquiera de las redes sociales simplemente por la estructura que cada uno de estos hipertextos posee.

Marquès Graells (2007) afirma que los estudiantes serán más autónomos en el acceso a la información en la construcción de sus conocimientos al trabajar con la Web 2.0 para lo cual necesitan competencias específicas, como las competencias digitales, que implica navegar (buscar o seleccionar en Internet), procesar la información con los medios informáticos para elaborar su conocimiento, expresarse y comunicarse con otros en el ciberespacio, conocer sus riesgos (plagio, spam, anonimato, falsedad) o usar las aplicaciones Web 2.0; además, implica las competencias sociales, como trabajo en equipo, respeto o responsabilidad. En términos más puntuales, sin embargo, aunque fuese posible considerar que un lector-usuario debe poseer una "competencia hipertextual", esta no puede ser un correlato exacto de la competencia textual, puesto que necesariamente implica las competencias digitales en general, por lo cual, de poder formularse, se compondría -entre otros- de los siguientes aspectos, partiendo del hecho de que el lector-usuario conoce y sabe usar la tecnología que da soporte a los textos digitales en general y al hipertexto en particular: el lector-usuario (1) conoce y sabe usar los motores de búsqueda; (2) es capaz de usar diferentes criterios de búsqueda para encontrar la información que requiere (palabras, frases, autores, nombres, etc.); (3) distingue los distintos tipos de hipertextos; es capaz de elaborar diferentes tipos de textos digitales (SMS, e-mail, blogs, documentos, etc.) con el formato y lenguaje adecuados; (4) es capaz de comprender diferentes tipos de textos digitales (SMS, e-mail, blogs, documentos, etc.) de acuerdo con el formato y lenguaje utilizados; (5) utiliza diferentes códigos que le permiten crear o comprender un texto multimodal; conoce los códigos visuales que le permiten recorrer los hipertextos (palabras marcadas en azul, íconos, etc.); (6) es capaz de utilizar hipervínculos que le permitan enlazar los distintos documentos cuando sea necesario; es capaz de incorporar diferentes componentes a un hipertexto: sonido, imágenes, hipervínculos, etc.; (7) aprende y reconoce diferentes rutas (uso de barras de herramientas, marcas de páginas favoritas, uso de tags o etiquetas, etc.) que le permiten interactuar de forma más rápida y fácil con los motores de búsqueda; (8) es capaz de

$\longrightarrow$


leer rápida y comprensivamente los contenidos que muestran los motores de búsqueda para determinar si la información es la requerida; (9) sabe cómo optimizar el tiempo cuando trabaja con hipertextos, por ejemplo, a través del uso de varias ventanas (programas, archivos o aplicaciones diferentes) o varias pestañas (diferentes páginas, portales, blogs, Messenger, etc.) en forma simultánea; es capaz de resolver problemas que surgen del uso de hipertextos a través de otros hipertextos (por ejemplo, tutoriales, foros, etc.); (10) distingue entre las páginas con credibilidad respecto de la información que entregan y las que no acreditan la información entregada; (11) distingue entre los hipertextos bien construidos (lingüística, visual y estructuralmente) de aquellos que no lo están; es capaz de interactuar en línea con otros usuarios (por ejemplo, en Google Docs, Messenger, foros, etc.); (12) sabe cómo guardar y compartir los hipertextos: puede fácilmente pasar de un hipertexto a otro a través del uso de ventanas o pestañas diferentes, hipervínculos, botones de acción, etc. Si bien es cierto que lo anterior es sólo una aproximación o posibilidad, se acerca a lo que un lector-usuario eficaz de los textos digitales -y no necesariamente un experto- es capaz de realizar y que va más allá de las tradicionales competencias textuales.

\section{Conclusiones}

A pesar de que los estudios textuales han evolucionado los últimos años, las propuestas de los años 70 y 80 siguen siendo aplicadas por gran parte del profesorado del sistema educacional chileno, lo cual puede explicarse porque formaron parte de su formación inicial docente, pero también porque si bien se ha avanzado notoriamente en el estudio del texto, estas teorías han demostrado ser sólidas y mantener su vigencia. Su aplicabilidad en el hipertexto resulta posible, pero no cabe duda de que se hace necesario abordarlo desde una perspectiva más actualizada, pues dichos estudios no consideran muchos de los aspectos que definen a los textos digitales.

Por otra parte, la inclusión de los textos digitales e hipertextos en Enseñanza Media es una necesidad, pues no sólo resultan habituales para los estudiantes, sino que constituyen uno de los principales instrumentos de la comunicación actual y de la adquisición del saber. Además de lo anterior, implica que el profesor posea las competencias digitales que le permitirán elaborar propuestas pedagógicas efectivas que relacionen los contenidos propios del subsector Lengua Castellana y Comunicación con las competencias digitales y que, especialmente, cumplan con una 
El hipertexto en la Enseñanza Media en Chile. ¿Es pertinente aplicar los enfoques textuales tradicionales? / Teresa Ayala

condición básica: si la actividad puede realizarse con lápiz y papel, entonces no se justifica el uso de la tecnología. El hipertexto ya no puede considerarse solo como un producto tecnológico, sino como el tipo de texto que resume y refleja a la sociedad de la información, por lo cual es pertinente incluirlo en el currículum de Enseñanza Media y, si los enfoques textuales tradicionales pueden ser aplicados, no debieran ser descartados, independientemente de que resulta necesario que el profesorado acceda a las nuevas teorías respecto de la lectura hipertextual y sus implicancias cognitivas. La forma en que se incorpore dependerá de las metodologías y de las condiciones externas, pero su presencia en la realidad cotidiana de millones de personas lo sitúa en un importante rasgo de la cultura del siglo XXI.

\section{Referencias bibliográficas}

Adam, J. M. (2009). Les textes: types et prototypes. París: Armand Colin. (1985). Le texte narratif: traité d'analyse pragmatique et textuelle. Paris: Nathan.

Albarello, F. (2011). Leer/navegar en Internet. Las formas de lectura en la computadora. Buenos Aires: La Crujía Editores.

Bassols, M.; Torrent, A. (2003). Modelos textuales: teoría y práctica. Barcelona: EUMO-OCTAEDRO.

Beaugrande, R. A. De; Dressler, W. U. (1997). Introducción a la lingüística del texto. Barcelona: Ariel.

Calvo Revilla, A. (2002). "Lectura y escritura en el hipertexto". Revista Espéculo $N^{0} 22$, UCM [en línea]. Disponible en http:// www.ucm.es/info/especulo/numero22/hipertex. html.

Cabedo Nebot, A. (2009). "Consideraciones gráficas y lingüísticas del lenguaje cibernético: el chat y el Messenger". Tonos Digital. Revista Electrónica de Estudios Filológicos $N^{o}$ 18, diciembre 2009 [en línea]. Disponible en http:// www.tonosdigital.com/ojs/index.php/tonos/article/ viewFile/341/240.

Canale, M. (1983). "De la competencia comunicativa a la pedagogía comunicativa del lenguaje". En La competencia comunicativa. M. Llobera (ed.) (1995). Madrid: Edelsam 63-81.

$+118$


Carr, N. (2011). Superficiales ¿Qué está haciendo Internet con nuestras mentes? México: Taurus

Gutiérrez, C. (2008). "La Web como espacio de información universal”. Cómo funciona la web. Santiago: Centro de Investigación de la web (CIW), Departamento de Ciencias de la Computación Universidad de Chile, 9-21.

Gutiérrez Valencia, A. (2006). "E-reading, la nueva revolución de la lectura: del texto impreso al ciber-texto". Revista Digital Universitaria, Vol. 7, N' 5 mayo de 2006 [en línea]. Disponible en http://www.revista.unam.mx/vol.7/ num5/art42/may_art42.pdf (visitado en noviembre 2009).

Hymes, D. (1976). "La sociolingüística y la etnografía del habla”. Antropología social y lenguaje. Buenos Aires: Paidós, 115-147.

Kress, G. y Leeuwen Van. T. (2001). Multimodal Discourse: The Modes and Media of Contemporary Communication Discourse. Londres: Arnold.

Lamarca Lapuente, M. J. (2006). Hipertexto: El nuevo concepto de documento en la cultura de la imagen [en línea]. Disponible en http:// www.hipertexto.info/documentos/caracter.htm.

Landow, G. (1995). Hipertexto. La convergencia de la teoría crítica contemporánea y la tecnología. Barcelona: Paidós.

Lévy, P. (1999). ¿Qué es lo virtual? Barcelona: Paidós.

Lotman, Y.; Uspenski B. A. (2000). "Sobre el mecanismo semiótico de la cultura". La semiósfera III. Semiótica de las artes y de la cultura. Madrid: Cátedra, 168-193.

Maingueneau, D. (1999). Términos claves del análisis del discurso. Buenos Aires: Ediciones Nueva Visión.

(2009). Análisis de textos de comunicación, Buenos Aires: Nueva Visión.

Marquès Graells, P. (2007). La Web 2.0 y sus aplicaciones didácticas [en línea]. Disponible en http://www.peremarques.net/ web20.htm.

Ministerio de Educación (2009). Propuesta de ajuste curricular. Objetivos Fundamentales y Contenidos Mínimos Obligatorios. Lenguaje y Comunicación [en línea]. Disponible en http://www.ediciones- sm.cl/ArchivosColegios/Chile/ 
El hipertexto en la Enseñanza Media en Chile. ¿Es pertinente aplicar los enfoques textuales tradicionales? / Teresa Ayala

Documentos/Cambios_Curriculares/2009_new/ LENGUAJEYCOMUNICACION_marzo.pdf

(2003). "Complex Information Processing: a File Structure for the Complex, the Changing an the Indeterminate". The New Media Reader. Noah Wardrip-Fruin, Nick Montfort (eds.), New York University Center for Advanced Technology. The MIT Press, 134-145.

Perrenoud, P. (2007). Diez nuevas competencias para enseñar. Barcelona: Ed. Graó.

Prado Aragonés, J. (2001). La competencia comunicativa en el entorno tecnológico: desafío para la enseñanza. Comunicar $17,21-230$.

Rodríguez De Las Heras, A. (2006). "Qué es un (hiper)texto". En ¿Qué es un texto? Madrid: Círculo de Bellas Artes.

Scolari, C. (2008). Hipermediaciones. Elementos para una Teoría de la Comunicación Digital Interactiva, Barcelona, Gedisa.

Vandendorpe, C. (2003). Del papiro al hipertexto. Ensayo sobre las mutaciones del texto y la lectura. Buenos Aires: FCE.

Van Dijk, T. (2005). Estructuras y funciones del discurso. México: Siglo XXI Editores.

Yus, F. (2010). Ciberpragmática 2.0. Barcelona: Planeta.

Zanoni, L. (2008 ). El imperio digital. El nuevo paradigma de la comunicación 2.0. Buenos Aires: Ediciones B.

$+120$

